\title{
A produção de vídeo por pessoas em sofrimento psíquico
}

\author{
The production of videos by people in psychic suffering \\ Cláudia Calheiros da Silva Suruagy \\ Professora do Colégio Santa Madalena Sofia \\ Mestre em Educação, Maceió, Alagoas, Brasil. \\ claudia-calheiros@hotmail.com
}

Deise Juliana Francisco Professora da Universidade Federal de Alagoas Doutora em Informática na Educação, Maceió, Alagoas, Brasil. deisej@gmail.com

Resumo: Trata-se de pesquisa-intervenção realizada com oficinas de produção de vídeo com usuários em sofrimento psíquico em um Centro de Atenção Psicossocial alagoano e ancora nas discussões entre educação, saúde mental e tecnologia digital de comunicação e informação. A ideia de relacionar esta pesquisa com a educação foi idealizada como forma de agenciar inúmeras possibilidades, buscando colocar o usuário como principal sujeito dentro do processo de construção, colocando em prática os pilares da educação. O objetivo foi analisar a produção de vídeo por usuários em seu potencial de reabilitação psicossocial. Participaram dezessete usuários inicialmente e, depois, cinco usuários trabalharam com a produção de um vídeo. Nas oficinas, os usuários se colocaram como sujeitos de suas aprendizagens, desenvolvendo protagonismo em seu cotidiano, havendo contribuição para o processo de reabilitação psicossocial. Os usuários foram construindo significados inseridos num movimento de reflexão-ação-reflexão.

Palavras-chave: Saúde Mental. Oficinas. Produção de vídeo. Educação.TDIC.

Abstract: This is an intervention research conducted with video production workshops with users in psychological distress at CAPS in Alagoas and is anchored in discussions between education, mental health and digital communication and information technology. The idea of relating this research to an education was conceived as a way to activate several possibilities, seeking the user as the main subject within the construction process, using the practices and pillars of education. The objective was to analyze the video production by users in their potential for psychosocial rehabilitation. Participate seventeen authorized users and then five users work with the production of a video. In the workshops, users place themselves as subjects of their learning, developing protagonism in their daily lives, having contributions to the psychosocial rehabilitation process. Users were constructing meanings inserted in movement of reflection-action-reflection.

Keywords: Mental Health. Video production. Education.TDIC. 


\section{O começo de uma produção}

O tripé já está montado. Iluminação, câmera e equipe prontas para começar. O diretor checa alguns pontos e dá início à produção do vídeo que registrará passagens da história da Produção de vídeo por pessoas em sofrimento psíquico. Assim, vislumbramos a possibilidade de caminhos abertos para a construção de um artigo na intersecção entre os campos da educação, da saúde mental e das tecnologias.

No Brasil, a discussão sobre a luta manicomial decorreu de lutas sociais que redundaram em um novo modelo da Psiquiatria (Lei 10216/2001). A partir daí, começou uma transformação na assistência em saúde mental, que oportunizou novas estratégias de cuidado para pessoas em sofrimento psíquico (BRAGA, 2019). Amarante (2007) afirma que a Reforma Psiquiátrica é um processo social complexo, de diferentes aspectos (epistemológico, técnico-assistencial, políticojurídico e sociocultural) que objetiva transformar as relações estabelecidas com a loucura. Aqui, restringimo-nos ao aspecto sociocultural por apostarmos que os meios de comunicação podem ser partícipes do processo de produção de vida.

A atual Política Nacional de Saúde Mental, baseada nos ideais de uma sociedade humanizadora e igualitária, busca a reinserção social na luta por uma sociedade livre da opressão, preconceito e discriminação. Uma das formas de intervenção preconizada pela política inclui oficinas terapêuticas, sendo que elas têm sido recriadas incorporando as Tecnologias Digitais da Informação e Comunicação (TDIC) em suas atividades, tanto como um meio de inclusão na chamada "era digital" quanto como uma possibilidade da habilitação psicossocial.

O vídeo, especificamente, oportuniza diversas maneiras de experimentações no que compete à difusão de conhecimento, de pensamento, de experiências mesmo. É determinado por seu caráter plural, diversificado (DUBOIS, 2004), sendo impossível prendê-lo numa forma estabilizada. Apesar de possuir proximidades com outras mídias, tem identidade própria como recurso tecnológico de informação e de comunicação: precisa de um tempo para ser produzido ou para ser visto, devido ao seu caráter atemporal; não possui repositório predefinido, por ser muito democrático e popular, encontrado em sites, blogs, redes sociais; não possui rigidez em sua constituição, é de natureza dinâmica e prática, se bem produzido, atinge seu objetivo facilmente, por envolver várias linguagens, a exemplo da verbal (oralizada e escrita), da não verbal, da gestual; não está aprisionado a padrões - a movimentos modelares pelo fato de permitir a criação, a imaginação fluir. A experiência com a produção de vídeo, desde o momento de sua concepção, filmagem, edição e posterior exibição, amplia a construção coletiva em redes de conversações que 
esgarçam a noção de consumidor e produtor. No âmbito da saúde mental, esgarçam a noção de sujeito e de doença.

Para este artigo, será trazida a experimentação de dois projetos que aconteceram e dialogaram ao mesmo tempo no decorrer da pesquisa: o trabalho com oficinas de vídeo e rádio com pessoas em sofrimento realizadas no Centro de Atenção Psicossocial (CAPS) do estado de Alagoas. As oficinas foram semanais com duração de uma hora e meia, para incluir digitalmente sujeitos em sofrimento psíquico acompanhados nesse serviço substitutivo ao manicômio, analisando a viabilidade da utilização das TDIC nas oficinas terapêuticas como forma de intervenção em saúde mental.

O trabalho realizado entre a Educação e a Saúde Mental acaba por se voltar para fazer intervenções a respeito do conhecimento dos usuários, a fim de que sua capacidade de reflexão e ação a respeito de tudo o que permeia sua existência no cotidiano seja ampliada. Para alcançarmos uma condição de pessoa com saúde, não precisamos apenas resolver os problemas de ordem biológica. Trata-se de ir muito além de tudo isso: faz-se imperativo uma ação integradora entre setores, para resolver necessidades de ordem cultural, religiosa, social, cultural, étnica, econômica que nos acometem no dia a dia e que acabam por interferir diretamente em nossa saúde.

O foco desta pesquisa está, então, assentado na intersecção entre perspectivas de educação não formal e saúde de pessoas em sofrimento psíquico, voltando-se para um trabalho com educação no contexto de serviços substitutivos ao manicômio, mediado pela produção de vídeo, voltado para o conhecimento dos sujeitos. O objetivo geral deste artigo é analisar a produção de vídeo por usuários do CAPS.

\section{Metodologia: Luz... Câmera... Ação!}

A expressão "Luz... Câmera... Ação!" é própria da linguagem do cinema e utilizado para iniciar a filmagem. A ideia de usar essas palavras está voltada para o fato de se verificar se tudo e todos os envolvidos estão preparados para dar início às gravações, elas servem como um ponto de partida. Mas, para se chegar à filmagem, um longo percurso já havia sido trilhado, o tema, a escolha dos personagens, o local, a criação do texto, o cenário, a escolha dos recursos. A cena que está prestes a iniciar traz esse processo, incluindo a gravação até chegar ao vídeo pronto. As luzes, as lentes e os olhares são direcionados para a saúde mental, a tecnologia e a educação. A "porta" desta pesquisa já foi aberta há muito tempo... bem antes... e continua aberta a outras criações, a novos roteiros 
Demonstraremos, agora, as portas que abrimos para a realização do trabalho - o tipo de pesquisa a ser realizado, o objeto de estudo, o porquê da seleção do tema, a pesquisa. A pesquisa de caráter qualitativo, por meio de uma pesquisa-intervenção, realizou-se no CAPS, localizado no estado de Alagoas. Segundo Aguiar e Rocha (2007, p. 657), é uma investigação participativa “[...] colocando em análise os efeitos das práticas no cotidiano institucional, desconstruindo territórios e facultando a criação de outros modos de existência”. E, conforme Cavagnoli e Maheirie (2019, p. 65): “Uma metodologia de pesquisa e de intervenção disposta a produzir não pode ignorar o imperativo ético dos bons encontros. Por isso, precisa engendrar relações que rompam com as hierarquias instituídas, em busca da transversalidade entre distintas perspectivas e da intersecção de práticas diversas".

Para a produção dos dados foram utilizadas observação participante, criação de diário de campo que foi escrito logo após o término de cada oficina, através do registro e da descrição de todos os acontecimentos. A análise foi realizada a partir da produção dos usuários do CAPS partilhada durante todo o processo de pesquisa, desde o primeiro até o último contato com eles, estando em constante diálogo com as proposições teóricas da pesquisa.

O método escolhido para o desenvolvimento desta pesquisa procura desestruturar as relações entre pesquisador e campo, para que oportunizem os aparecimentos inventivos e de alteridade. Nesse processo, nós, pesquisadoras, colocamo-nos na condição de mediadoras, vetores de passagem de um território a outro, numa proposta ético-política na construção da trajetória da investigação.

No início, a pesquisa contava com 17 usuários adultos em sofrimento psíquico atendidos pela unidade e, devido a sua situação socioeconômica, dependiam exclusivamente do tratamento ofertado pelo CAPS. Alguns já eram aposentados (ou beneficiários financeiros de programas de assistência de renda mensal do governo).

De acordo com Gohn (2020), na educação não-formal, algo básico a ser considerado é o de que a aprendizagem acontece na prática social - o trabalho coletivo, realizado de forma coletiva, é que produz aprendizagens. Neste aspecto, as oficinas se apresentam como possibilidade, que, agregadas a outros processos, podem colaborar para a reabilitação psicossocial do sujeito, e valorizar a história de vida com suas particularidades e regionalidades de forma que este sujeito se sinta acolhido. Tal como discutem Pereira, Barbosa e Rezende Filho (2019, p. 4) "a oficina de cinema desenvolvida pelo projeto previu ações voltadas tanto para a formação do espectador quanto para uma abordagem das técnicas de filmagem em um ambiente que possibilitasse a troca de experiências, a horizontalidade e o diálogo entre os participantes". Nesse contexto, entende-se 
que as oficinas possibilitam a reabilitação, levando em consideração o ritmo de cada um. Durante as atividades das oficinas, o usuário era o foco de toda a atenção desenvolvida. Além disso, o usuário era constantemente estimulado a interagir com o grupo e com os profissionais. O trabalho foi organizado em sete etapas, conforme explicitado no Quadro-resumo.

Quadro 1 - Etapas da pesquisa

\begin{tabular}{|c|c|c|c|}
\hline Etapa 1 & Socialização & $\begin{array}{c}\text { Apresentação dos pesquisadores, dos usuários e } \\
\text { da pesquisa propriamente dita }\end{array}$ & $\begin{array}{l}1 \text { encontro de } \\
\text { duas horas }\end{array}$ \\
\hline Etapa 2 & Motivação & $\begin{array}{l}\text { Fomento do interesse dos usuários para } \\
\text { participação da oficina de vídeo e rádio }\end{array}$ & $\begin{array}{l}2 \text { encontros de } \\
\text { duas horas }\end{array}$ \\
\hline Etapa 3 & Filmagem & Filmagem de uma oficina de culinária & $\begin{array}{l}2 \text { encontros de } \\
\text { duas horas }\end{array}$ \\
\hline Etapa 4 & $\begin{array}{l}\text { Conhecendo a } \\
\text { Máquina }\end{array}$ & $\begin{array}{l}\text { Realização de diversas atividades de } \\
\text { familiarização com o computador }\end{array}$ & $\begin{array}{l}3 \text { encontros de } \\
\text { duas horas }\end{array}$ \\
\hline Etapa 5 & Edição & Uso do Movie Maker & $\begin{array}{l}3 \text { encontros de } \\
\text { duas horas }\end{array}$ \\
\hline Etapa 6 & $\begin{array}{l}\text { Apreciação do } \\
\text { Vídeo }\end{array}$ & $\begin{array}{l}\text { Exposição do vídeo a toda a comunidade do } \\
\text { CAPS }\end{array}$ & $\begin{array}{l}2 \text { encontros de } \\
\text { duas horas }\end{array}$ \\
\hline
\end{tabular}

Fonte: A autora (2017).

A pesquisa seguiu os critérios da ética contidos na Resolução 496/12 e Resolução 510/2016, levando em consideração na pesquisa os quatro referenciais basilares da bioética: a não maleficência, a autonomia, a justiça e a beneficência. O Termo de Consentimento Livre e Esclarecimento (TCLE) foi apresentado aos participantes legalmente responsáveis por si mesmos, sendo assinado nas dependências do CAPS.

\section{Resultados de um trabalho de produção}

Pelas lentes do conhecimento, enxergamos os (des)caminhos que nos conduzem a novas filmagens da vida. Durante o decorrer das oficinas de vídeo, pudemos vivenciar inúmeras experiências que nos possibilitaram outros olhares para aquilo que já estava posto no CAPS onde o trabalho estava sendo realizado. Foram várias as atividades efetuadas na busca por visões 
possíveis para um cenário já tão fatigado nas retinas do cotidiano. A fim de potencializar os olhares, as gravações de áudio e de imagens, o uso do computador, tudo foi iniciado com grande motivação. Os objetos ou materiais incorporados à oficina, a cada tempo, (res)significavam a experiência de produção do objeto cultural intitulado de vídeo.

A análise de percepções aconteceu nos primeiros contatos com os sujeitos, durante as oficinas e no momento das anotações sobre os comentários que eles faziam. As etapas das oficinas foram acompanhadas com registros em diários de campo - o que contabilizou 62 horas de atividades. As oficinas foram realizadas de acordo com a disponibilidade dos usuários no CAPS algumas foram feitas no espaço de convivência e outras durante a última oficina de vídeo e de rádio, todas gravadas em celular, com a anuência de cada sujeito. Ainda foram acrescidas às análises perceptivas, as falas que representaram o que pudemos extrair sobre a caracterização da qualidade das oficinas.

Os usuários foram denominados por nomes fictícios para manter o anonimato de sua identidade. No início, dezessete usuários, entre eles dez do sexo feminino e sete do sexo masculino, participaram da primeira oficina. A idade dos sujeitos varia de 18 a 55 anos de idade, seu grau de instrução: dez tinham o Ensino Fundamental incompleto, três tinham o Ensino Fundamental completo, três tinham o Ensino Médio completo, um tinha o Ensino Médio incompleto. Essa informação nos trouxe a percepção de que a maioria tem dificuldades para se manter um tempo maior dentro da escola; por causa disso, possuem baixa escolarização, sendo que a média de tempo de escola foi de 4 a 6 anos. Quanto ao estado civil, assinalaram o fato de nenhum dos usuários possuir relacionamento estável com alguém. Os participantes não relataram ter profissão; no máximo, segundo eles, fizeram "bicos" (trabalhos rápidos de pedreiro, de faxineiro, de pintor etc., por conta própria), quando eram solicitados, na casa de vizinhos. A média de tempo que os sujeitos frequentavam o CAPS variava entre 2 a 6 anos. Apenas um dos sujeitos tinha tido contato direto com o computador. Para os demais, a máquina era uma novidade - tanto o era que somente cinco usuários do CAPS aceitaram participar do trabalho por envolver a ferramenta de maneira direta. Mesmo o que tinha computador em casa, não recebia autorização da família para usar a máquina, sob pena de quebrá-la - isso demonstra a falta de credibilidade que o próprio usuário sofre dentro de sua casa por parte de seus familiares. Posteriormente, participaram cinco usuários.

Na Etapa 1, a da Socialização, reforçamos o fato de os usuários se observarem, agora, como singulares em suas percepções. Convidamos os usuários para fazer gravações de pequenos vídeos com o nosso celular, a fotografar o que quisessem eternizar em um clique, dentre outras atividades que os deixassem motivados, a partir do uso do aparelho. A relação com os recursos 
tecnológicos, portanto, foi acontecendo de forma gradativa, curiosa, sempre no coletivo e baseado no diálogo, buscando proporcionar espaços de voz e de decisão compartilhada.

No primeiro exercício de filmagem, dois usuários se candidataram e ainda tiveram a ideia de fazer uma filmagem apresentando o CAPS; começaram a partir do portão e percorreram todas as dependências, mostrando as salas, para que são usadas e quem trabalhava lá. Depois da gravação concluída, os usuários foram reunidos em círculo e assistiram à gravação feita por Sérgio e Madalena. Eles se viam na gravação. Ao virem a filmagem trêmula, o Sérgio logo afirmou que ficou assim porque estava muito nervoso, sua mão tremia muito. Pensamos que as experiências de produção videográfica marcam a singularidade e autoria do sujeito que a ela se acopla ampliando uma rede de conversações, ao fixar a obra de sua criação na superfície da imagem.

Tudo o que foi produzido foi socializado na rádio, criada no decorrer do projeto, para que todos eles conhecessem o trabalho uns dos outros. Ao finalizar o primeiro momento, lançamos para o grupo o desafio de construirmos um vídeo; eles ficaram em silêncio por um tempo e um pouco assustados por não conhecerem o computador. Nenhum deles tinha celular, então perguntamos quem gostaria de realizar uma pequena gravação no CAPS com os nossos celulares, três se disponibilizaram a fazer a atividade. Ana gravou o CAPS, fez uma apresentação do local, das salas e dos funcionários, depois todos assistiram à gravação. Foi muito interessante observar a felicidade no rosto deles ao visualizar a sua produção na tela e saber que tinham conseguido, que foram capazes - isso encorajou os demais usuários a se envolverem mais nas atividades.

Essas gravações aconteceram como forma de motivação para que conseguíssemos realizar a atividade proposta no CAPS, que era uma oficina de produção de vídeo.

A utilização de dispositivos tecnológicos, ao mesmo tempo em que possibilita a produção de novas relações dos sujeitos com os quais o projeto trabalha, também provoca deslocamentos entre participantes do projeto de pesquisa e trabalhadores do CAPS. A interação com outros domínios tecnológicos traz a necessidade de ocupação com as máquinas - computadores, câmeras fotográficas, vídeos. Esse é um dos pontos mais desafiadores para os que propõem a utilização da tecnologia como instrumento de intervenção em saúde mental. Tal como afirma Kastrup (2001), o território mais indicado para a invenção é aquele em que nem sabemos mais se o que fazemos é psicologia ou educação, terapia educacional, enfermagem, medicina...), o ambiente vai se tornando um lugar de aprendizagem mútua e contínua. Também começávamos a perceber o quanto eles podiam produzir se fossem estimulados e assistidos em suas demandas; e que, independentemente de qualquer situação, o outro sempre tem algo a nos ensinar. 
Realizamos a Etapa 2, intitulada de Motivação. Foi o momento em que fomentamos o interesse dos usuários para a adesão à proposta de produzir um vídeo e de criar uma rádio. Cinco usuários demonstraram interesse e sugeriram gravar um evento de culinária, usando, para isso, a cozinha do CAPS. Eles tinham vontade de aprender a fazer algum alimento para poder ter uma autonomia financeira. A partir disso, foi organizada uma oficina para ensinar a fazer trufas. Alguns sugeriram gravar um vídeo mostrando como ensinar a fazer uma receita; oferecemos, então, nosso celular a fim de eles produzirem pequenas gravações. A partir disso, ficou decidido pelo grupo que seria uma oficina de culinária, eles iriam ensinar a fazer trufas, a ideia era a de que eles aprendessem e ensinassem através do vídeo aos telespectadores a preparar algo que pudesse contribuir para a sua ressocialização e sua inserção no mercado de trabalho, mesmo que fosse o informal.

$\mathrm{Na}$ Etapa 3, a da Filmagem, os usuários filmaram, com o uso do celular, a oficina de culinária na cozinha do CAPS. O momento foi de grande interação. Juntos, os usuários se envolveram na ação, para realizar a atividade com perfeccionismo. Ficamos apenas com um grupo de cinco usuários, quatro mulheres e um homem, o qual foi o responsável por toda a organização da ação de filmar, pelo fato de ter interesse por aparelhos tecnológicos muito mais do que os outros (também por não ter medo de manusear o celular). Primeiramente, o filme foi pensado por todos para ser posto, depois, em prática. Os cinco usuários estruturaram o passo a passo, sob nossa orientação, de como o vídeo seria criado. Pusemos no papel a seguinte organização: Passo 1: a escolha do que seria filmado com o celular; 2. a decisão do como seria filmado; 3. o momento da filmagem; a filmagem; 4. a avaliação da filmagem; 5. a refilmagem, caso fosse necessário; 6. a socialização do produto para análise de todos os envolvidos na pesquisa.

Ressaltam que nunca tinham tido a oportunidade de fazer uso das ferramentas, mas o fizeram com bastante tranquilidade e maestria. Ao organizar a oficina, tivemos toda uma preocupação e todo um cuidado com o processo de higienização e produção. Também foi trabalhado com eles o quanto foi gasto com o material comprado, com o gás, com o tempo, para que se pudesse calcular o valor do produto a ser comercializado com a margem de lucro necessária. Sendo assim, a atividade foi gravada pelo José, que alternava momentos da gravação com a Ana. Maria, Paula e José ficaram com a responsabilidade de conduzir os trabalhos dentro da cozinha. Eles ensinaram como preparar uma receita de trufas de coco. Primeiramente se apresentaram, explicaram o que iam ensinar e em seguida foram demonstrando passo a passo as etapas da receita. Sobre isso, de acordo com (KASTRUP, 2001, p. 35), “Aprendizagem não é entendida como passagem do não-saber ao saber (...), nem é uma transição ou uma preparação que desaparece com 
a solução ou resultado. A aprendizagem, é sobretudo, invenção de problemas, é experiência de problematização".

Todo o processo de aprendizagem sobre como produzir trufas foi realizado com o envolvimento ativo dos usuários, que queriam realizar tal ação com grande responsabilidade, para que realente desse certo. Desafiados, eles não desejavam fazer de qualquer forma. Ao contrário, só falavam em expor para toda a comunidade do CAPS o melhor que pudessem fazer. E assim o fizeram. No depoimento da Maria, ficou claro o seu processo de evolução diante do trabalho realizado. De início, a insegurança, cristalizada no nervosismo. Depois, a consciência da capacidade de transformar a própria realidade, ao relatar a possibilidade de se tornar uma empreendedora de sua própria história. No discurso Joana, evidenciou-se a visão da família como condição limitante do seu próprio desenvolvimento.

Daí o receio existente diante do novo e a superação a partir da oficina proposta. Com a Ana e a Paula, o resultado não foi diferente dos outros dois. Estas, assim como os demais, também vislumbraram um futuro promissor, ao citar seu processo de possível probabilidade de ganhar dinheiro com o próprio trabalho, advindo do aprendizado com a oficina de produção de vídeo no CAPS. José, por fim, coroou o sentimento de todos em sua fala, ao trazer a metáfora do artista da TV Globo, entendida como aquele que é visto por todos como pessoa apta para trazer para si mesmo os holofotes da vida, por ter brilho, talento, capacidade de produção, de trabalho - de vida em abundância.

Ao concluirmos as filmagens e gravações para a edição do vídeo, os usuários participaram da Etapa 4, chamada de Conhecendo a máquina. Eles tiveram contato direto com o computador, algo desconhecido e inusitado para alguns. O objetivo era familiarizar o usuário com a máquina, preparando-os para usar o Movie Maker, editor de vídeo simples, que é facilmente manipulado no sentido de editar produções caseiras por pessoas que estão iniciando a tarefa de edição de vídeos. Nesta etapa, tiveram o contato direto com o computador. Preparamos uma atividade de socialização entre os sujeitos e a máquina, com o objetivo de desenvolver a familiarização com o instrumento e de estabelecer a segurança para desenvolver a etapa proposta. Disponibilizamos três computadores. Eles se reuniram em dupla e de forma individual também para conhecer o aparelho mais de perto. Sobre isso, Fernandes (2011) aponta que a utilização de TDIC apresenta-se como um meio de contribuição no aprendizado do usuário em sofrimento psíquico, de forma ativa, na busca pelo conhecimento (das letras maiúsculas, das minúsculas, dos números, do lugar do espaço, do enter, do deletar, do mouse, etc.). Esse momento foi muito 
interessante, pois eles se sentiram amedrontados, inseguros; ao mesmo tempo, porém, desejosos de aprender a manusear a máquina.

Apresentamos para os usuários o programa editor de texto e pedimos para que digitassem o que quisessem, aos poucos foram conseguindo digitar o próprio nome e até pequenas frases. $\mathrm{O}$ objetivo era prepará-los para usar o programa de edição de vídeo, o Movie Maker. Foi um momento mágico para os cinco usuários que estavam participando ativamente da oficina, eles falavam que "nunca imaginaria conseguir nem ligar um computador, imagine "escrever", "um sonho", e ainda diziam que "nós, pesquisadoras, erámos umas santas". Muitas vezes, os usuários davam sugestões e faziam algumas colocações, como: "Você é corajoso, queria muito mexer no computador, mas tenho muito medo". Já outro dizia: "Estou aprendendo com vocês". Percebemos que, de uma forma ou de outra, todos estavam envolvidos com o processo; aprendendo e transformando, iam interagindo, no jeito de pensar, de agir ou até mesmo na maneira de ver as situações. Kastrup (2008, p. 40), sobre isso, assinala que “(...) A interação entre os usuários e as tecnologias não como a solução de problema ou a busca incansável pela cura, porém como invenção de problemas, isto é, uma problematização que "leva à invenção de novas formas de conhecer", de novas formas de conhecer e interagir com o mundo.

Em outro momento, na Etapa 5, a da Edição, os usuários do CAPS transportaram a filmagem do celular para o computador, a fim de editarem o vídeo gravado. O momento exigiu deles grande poder de concentração e de destreza com as ferramentas disponíveis na máquina, para executar a atividade com êxito. Apresentamos para os usuários, através do Data Show, o Movie Maker, um editor de vídeo simples, feito para editar produções caseiras por pessoas que estão iniciando na tarefa de edição de vídeos. Ficaram assustados, afirmando que não iam conseguir, que era muito difícil. Dos cinco participantes, o mais seguro era o que já sabia manusear o computador. Fizemos uma apresentação para mostrar o passo a passo do programa e a sua utilidade para a realização da atividade proposta. Depois de concluída a atividade, os usuários iniciaram o processo edição do vídeo sobre culinária, com a nossa ajuda. Aos poucos, foram organizando o material para deixá-lo pronto para ser apreciado pelos participantes do CAPS.

Durante a etapa de edição do vídeo, os usuários escolheram a trilha sonora do vídeo. Um usuário sugeriu a música Maluco Beleza, de Raul Seixas, justificando que teria que colocar uma música que tivesse relação com eles, eles conversaram e algumas das falas eram: "A sociedade acha que somos loucos, somos perigosos, pessoas que amedrontam, incapazes"; "As pessoas que se dizem 
normais são mais loucas do que nós"; "Nós somos rejeitados pelas pessoas"; "Quem frequenta o CAPS é louco". Guerra (2004, p.96) afirma que "As oficinas são construídas a partir da participação e da produção na cultura, abrindo para o portador de sofrimento psíquico a possibilidade de reinscrever-se nas relações pessoais, de circulação, de trocas, de trabalho, enfim, do cotidiano".

Isso ficou perceptível a cada encontro com os usuários - eles traziam ideias inteiras montadas em suas cabeças, e, conosco socializavam-nas, a respeito do que gravariam no vídeo, como gostariam que o vídeo ficasse, o que poderiam gravar em novos filmes a serem feitos depois do da pesquisa, trazendo para o lado educativo, proporcionando, com isso, um bom desenvolvimento da oralidade e da escrita, por meio de mecanismos de ensino e aprendizagem que envolvem lazer e produção de conhecimentos. Cavalini (2020) aponta o quanto as artes podem compor com os CAPS, no sentido de criação de outros mundos e estéticas.

Na Etapa 6, a da Apreciação do vídeo, o produto foi exibido para uma plateia composta por técnicos e usuários do CAPS, momento de protagonismo dos usuários, por terem participado ativamente como atores e autores do processo. Momento também de satisfação para os usuários e para todos os envolvidos com a pesquisa. Para isso, convidamos, além dos usuários da instituição, os profissionais do CAPS, para a apreciação do vídeo editado e pronto. Foi um momento de muita expectativa, de muita emoção (Tudo pronto!). Os trabalhos foram apresentados um a um para a plateia que os assistiam envaidecida e feliz por presenciarem uma ação de autonomia e de autoria realizada pelos usuários atendidos por eles (os servidores da instituição). O que mais chamou a atenção no momento da apresentação do vídeo produzido foi a felicidade e a satisfação dos envolvidos diretamente com o trabalho. Os sentimentos de cidadania preencheram seus discursos. Eles se sentiram incluídos no meio, por saber de suas potencialidades e de nelas acreditar; por vivenciarem o respeito por si mesmos e pelo outro de forma mais efetiva (e, com isso, a desconstrução da ideia de que saúde mental é doença, porque não o é - é apenas uma nova dimensão da vida) deu a cada usuário envolvido no trabalho a certeza de que eles podem mais, bem mais do que disseram que eles podiam, no início da pesquisa. Outro ganho aconteceu com os familiares deles, que foram pegos de surpresa com o trabalho realizado pelos usuários no CAPS um novo olhar acerca das potencialidades dos usuários foi “acordado” para a família!

Ao longo do processo, acompanhamos o desenvolvimento dos usuários, com o objetivo de identificarmos as possibilidades e as contribuições das oficinas terapêuticas informatizadas a serviço dos sujeitos. Percebemos que a reabilitação também é possível a partir do trabalho construído por meio de direitos primordiais da cidadania, que envolvem os aspectos afetivos, 
relacional, material, habitacional e produtivo, em uma dimensão que englobe todos aqueles que estão excluídos desses direitos primordiais e necessários à construção de sua cidadania.

Segundo Trindade e Becker (2011), a relação com o coletivo melhora a comunicação e a oralidade que era anulada devido a uma postura fechada e introspectiva. Os usuários descobriram o sentimento de pertencimento ao ver o vídeo, algumas construções autônomas e singulares os instigaram no momento (e acreditamos que será levado por toda uma vida). Após as etapas, passamos para a apresentação das categorias de análise conforme os objetivos da pesquisa, quais sejam: 1. analisar a relação dos usuários com as TDIC; 2 . mapear a produção de vídeo desenvolvida pelos usuários; e 3. perceber dos usuários o que eles conseguiram extrair da experiência com as oficinas.

Ficou muito exposto o medo da tecnologia sentido pelos usuários; esse universo parecia algo muito distante do mundo deles e até mesmo desnecessário em suas vidas. Simondon (2007) desconstrói a visão negativa que se tinha dos objetos técnicos e afirma que eles fazem parte da nossa prática, da nossa cultura, e, quando negado, estamos renegando parte da nossa própria realidade humana, o objeto técnico nunca seria um elemento isolado nele mesmo, sempre se coloca à disposição para manter relação com o homem ou com outras técnicas.

Simondon (2001) afirma que na relação homem-máquina existem ideias controversas a respeito da máquina: a primeira é a de entendê-la como objeto de uso e a segunda é a de compreendê-la como adversária do homem. No entanto, o autor conclui que automatismo e aperfeiçoamento tecnológico são coisas distintas, mas ao mesmo tempo com certa margem de indeterminação. Sendo assim, o homem poderia ser visto como mediador, um facilitador ou até mesmo protagonista no uso das máquinas, conhecendo-a tão bem chega até a pensar na sua existência a partir delas.

Esse acoplamento homem e máquina foi constatado a cada atividade realizada, o avanço e a intimidade com o objeto técnico proporcionavam sentimentos de conhecimento, de familiaridade, de alegria e de satisfação deles no desenvolvimento do processo: sentiam-se úteis, ocupados e capazes.

Partindo dessa premissa, concluímos que a relação homem-máquina não apresenta um modelo pronto e acabado, sendo assim não haveria espaço para criação a partir do uso do objeto técnico. O envolvimento e o crescimento cognitivo dos usuários envolvidos, durante o processo, mostravam-se em ascensão. Víamos isso através das respostas que eles davam às demandas do trabalho em desenvolvimento. É possível vislumbrar tal afirmação a partir dos depoimentos dos participantes nas gravações iniciais. 
Eu consegui gravar um vídeo! Nunca imaginei que um dia eu pudesse fazer uma coisa dessas, vou comprar um celular para fazer um monte de vídeo. (Ana) Fiquei muito feliz por ter conseguido fazer essa gravação, eu achava que era muito difícil, ficou meio tremendo um pouquinho, mas ficou boa. (Maria) Meu Deus, eu consegui! Fiquei muito nervosa, mas adorei! (Ana)

Por meio das oficinas de vídeo, os usuários puderam conhecer e aprenderam a manusear a máquina, aprenderam a filmar, a editar; ocorrendo, assim, aprendizagem dos recursos informatizados. O trabalho de autoria desde a escolha do tema do conteúdo da filmagem até a produção vídeo possibilitou a cada um a descoberta e o reconhecimento do seu potencial, estendendo-se aos profissionais do CAPS. O vídeo abre espaço para a expressão oral e a corporal, instiga a imaginação e a autonomia. É um tipo de atividade que desencadeia uma aprendizagem colaborativa, interativa, que estreita laços, fortalece alianças entre os autores do processo da produção. Miranda (2007) afirma que o audiovisual contribui para a compreensão de "vídeoprocesso", na medida em que a sua produção acontece de forma coletiva e compartilhada, remetendo à ideia de autoria. Conforme Rodrigues Junior (2019, p. 90) "O universo subjetivo que envolve as linguagens artísticas proporciona uma forma diferente de se entender o mundo e de lidar com aspectos internos como emoções, sentimentos e imagem de si”, sendo importante para a intervenção em saúde mental.

De acordo com as falas dos usuários, as oficinas de produção de vídeo significaram ainda tudo isto: 1. o desejo de recuperação tanto por parte dos usuários como por parte de seus familiares; 2. um espaço aberto para a criação e para a liberdade; 3. momentos inesquecíveis da expressão de emoções de distintas formas; 4. períodos intensos de autoafirmação; 5. um lugar de múltiplas expressões; 6. uma válvula de escape para as problemáticas da vida; 7. ocasiões propícias para o desenvolvimento da oralidade; 8. oportunidade para o progresso do pensar, da suavidade da individuação.

Francisco (2007) afirma que os usuários em sofrimento psíquico se tornam atores principais das suas atividades, e tudo aquilo que eles produzem pode ser enxergado como meio para reconhecer seus potenciais diante dos seus familiares, dos funcionários de saúde mental e da sociedade, a partir da sua participação nas oficinas na área de saúde mental nos serviços substitutivos.

Daí a importância de os tratamentos que ocorrem em instituições, como os CAPS, terem um trabalho diversificado, que caminhe para além do medicamentoso, do clínico. Nas oficinas, os usuários se colocaram como sujeitos de suas aprendizagens, desenvolvendo um protagonismo em seu cotidiano no que diz respeito à demanda de construir sentidos diante do que a eles é 
apresentado. A relação homem-máquina se dá de forma bem natural neste modelo de ensinoaprendizagem. Os usuários vão construindo significados inseridos num movimento de reflexãoação-reflexão.

$\mathrm{Na}$ educação, a construção de conhecimento não ocorre necessariamente dentro de um ambiente físico, escola, ela ultrapassa esses limites territoriais. Todos os envolvidos passaram a ser partícipes, configurando um espaço interdisciplinar de construção de significados. Essa relação de participação existe por causa da riqueza de todos os sujeitos, num constante diálogo entre o científico e os saberes vividos. Trata-se de ir além da educação formal, centralizadora de assuntos a serem ministrados de forma sistematizada. Ao contrário disso, conforme aconteceu nesta pesquisa, os objetivos foram criados a partir de cada intervenção realizada, de tal modo que fez com que todos os sujeitos ficassem curiosos e autores das próprias intervenções. A formação de profissionais, no universo da educação não formal, pode acontecer através de oficinas, de trabalhos em equipes, de cursos, de trocas de experiências. De acordo com Gohn (2020), na educação nãoformal, algo básico a ser considerado é o de que a aprendizagem acontece na prática social - o trabalho coletivo, realizado de forma coletiva, é que produz aprendizagens.

\section{Considerações finais}

Ao frequentar o CAPS, íamos sendo afetadas não só por estarmos conduzindo as atividades com os usuários, mas também por estarmos presas aos medos. Tínhamos muito receio de que os trabalhos das oficinas pudessem gerar algum tipo de problema em algum usuário, talvez pelo estigma criado pela sociedade, o louco. Fomos descobrindo que ali era um espaço que abre um leque de possibilidades para esses usuários inventarem novas formas de existir. Também não cabia a nós assumir uma postura de detentoras do saber, e que estávamos ali apenas para colocar em prática uma atividade predeterminada, ali passou a ser um lugar de criação, seria o mesmo que classificar, ordenar e codificar a realidade, e nesse caso específico, os usuários. Estabelecemos ali um entendimento de que existe vida, não aquela vida inútil, fraca, débil, mas uma vida que se desvincula desse formato e que também se movimenta, que circula, que anseia por novas maneiras de existir.

Os recursos audiovisuais fizeram a mediação do nosso conhecimento de mundo, trazendo à tona diversificadas maneiras de representar a realidade, mostrando o mesmo objeto a partir de uma outra perspectiva, levando-se em conta os sons, os lugares, os movimentos. Na oficina de culinária, por exemplo, a mediação aconteceu de maneira colaborativa. Os oficinandos, de posse 
da receita de trufas, foram se articulando, para que produzissem o alimento da melhor forma possível.

Ao chegarmos ao CAPS, encontramos vários usuários que já não queriam mais falar sobre a doença, ou falar de suas angústias sobre a difícil convivência com a família. Depois de um tempo de permanência nossa, os usuários, quando nos encontravam, logo perguntavam: "Hoje vai ter vídeo?". Uma pergunta simples, que, ouvida por qualquer pessoa que não partilhava conosco daquele lugar-oficina, poderia soar como mero perguntar, ou querer ser informado sobre. Mas a pergunta ultrapassava tudo isso para nós. Nós sentíamos ainda uma expectativa dos usuários pelo dia da oficina que nos motivava a continuar o trabalho com grandes expectativas. Em muitos dias de trabalho, ouvíamos a mesma frase: “Já acabou?” Ou então: “Só teremos mais oficina na semana que vem?".

A produção dos vídeos pelos usuários em sofrimento psíquico fundamentou-se em três dimensões: epistemológica, estética e do cuidado em saúde mental, na medida em que a produção de subjetividade singularizada funciona maquinando modos de existência, que modelam as maneiras de sentir e de pensar, fazendo do exercício da subjetivação uma ferramenta estética e de reabilitação dos usuários em sofrimento psíquico.

\section{Referências}

AGUIAR, K.; ROCHA, M. Micropolítica e o exercício da pesquisa intervenção. Referências e dispositivos de análise. Psicologia Ciência e Profissão, v. 4, n. 27, p. 648-663. 2007.

AMARANTE, P. (coordenador). Saúde Mental e atenção psicossocial. Rio de Janeiro: Ed. Fiocruz, 2007.

BRAGA, C. P. A perspectiva da desinstitucionalização: chaves de leitura para compreensão de uma política nacional de saúde mental alinhada à reforma psiquiátrica. Saúde e Sociedade [online]. v. 28, n. 4 [Acessado 29 Junho 2020] , pp. 198-213. Disponível em: <https://doi.org/10.1590/S0104-12902019190125>. ISSN 1984-0470. https://doi.org/10.1590/S0104-12902019190125.

BRASIL. Ministério da Saúde (BR). Secretaria de Atenção à Saúde. Ministério da Saúde (BR). Relatório de Gestão: 2003-2006. Saúde mental no SUS: acesso ao tratamento e mudança do modelo de atenção. Brasília (DF); 2008.

CAVAGNOLI, Murilo; MAHEIRIE, Katia. A cartografia como estratégia metodológica à produção de dispositivos de intervenção na Psicologia Social. Fractal, Rev. Psicol., Rio de Janeiro, v. 32, n. 1, p. 64-71, Apr. 2020. Available from

$<$ http://www.scielo.br/scielo.php?script=sci_arttext\&pid=S1984- 


\section{Dialogia}

SURUAGY, Cláudia Calheiros da Silva; FRANCISCO, Deise Juliana. A produção de vídeo por pessoas em sofrimento psíquico

02922020000100064\&lng=en\&nrm=iso $>$. access on 04 July 2020. Epub Apr 09, 2020. https://doi.org/10.22409/1984-0292/v32i1/5680.

CAVALLINI, Flávia de Macedo. CAPS, ateliês e oficinas: artes no mundo, mundos na arte. Fractal, Rev. Psicol., Rio de Janeiro, v. 32, n. 1, p. 40-45, Apr. 2020. Available from $<$ http://www.scielo.br/scielo.php?script=sci_arttext\&pid=S1984-

02922020000100040\&lng=en\&nrm=iso > . access on 04 July 2020. Epub Apr 09, 2020. https://doi.org/10.22409/1984-0292/v32i1/5671.

DUBOIS, P., Cinema, vídeo, Godard. São Paulo: Cosac y Naif, 2004.

FERNANDES, C. A pesquisa em sala de aula como instrumento pedagógico: considerações para sua inclusão na prática pedagógica. Diálogos Educacionais em

Revista. Campo Grande, v. 2, n. 2, 2011. Disponível

em:<http://dialogoseducacionais.semed.capital.ms.gov.br/index.php/dialogos/article/vie w/22/ 51> Acesso em: 06 abr. 2017.

FRANCISCO, D. Criando laços via recursos informatizados. 2007. 172 f. Tese (Doutorado em Informática na Educação), Universidade Federal do Rio Grande do Sul, Porto Alegre, 2007.

GOHN, M. Educação não formal: direitos e aprendizagens dos cidadãos (ãs) em tempos do coronavírus. Revista Humanidades e Inovação v.7, n.7.7 - 2020.

GUERRA, A. Oficinas em saúde mental: percurso de uma história, fundamentos de uma prática. In. COSTA, C; FIGUEIREDO, A. (org.). Oficinas terapêuticas em saúde mental: sujeito, produção e cidadania. Rio de Janeiro: Contra Capa, 2004.

KASTRUP, V. Aprendizagem, arte e invenção. Psicologia em Estudo, v. 6, n. 1, p. 17-27, jan./jun. 2001.

MACHADO, D. ; GOTTEMS, L.; PIRES, M. Aprendizagem em saúde mental por meio da produção videográfica: relato de experiência. Texto contexto - enferm., v. 22, n. 4, p.1205-1213, 2013.

MIRANDA, L. Consumo e produção de subjetividade nas TVs comunitárias. Revista do Departamento de Psicologia, v. 19, n. 1, p. 199-214, jan/jun, 2007.

PEREIRA, G.; BARBOSA, M. I. B.; REZENDE FILHO, L. A. C. de. Ouvindo imagens: ensaio sobre uma oficina audiovisual inclusiva de cinema e educação. Pro-Posições, Campinas, v. 30, e20180041, 2019. Available from $<$ http://www.scielo.br/scielo.php?script=sci_arttext\&pid=S0103-

$73072019000100545 \& \operatorname{lng}=$ en\&nrm $=$ iso $>$. access on 04 July 2020. Epub Dec 02, 2019. https://doi.org/10.1590/1980-6248-2018-0041.

RAUTER, C. Oficinas para quê? Uma proposta ético-estético política para oficinas terapêuticas. In AMARANTE, Paulo (org.). Ensaios: Subjetividade, saúde mental, sociedade Rio de Janeiro: Fiocruz. 2000.

RODRIGUES JR, A. Saberes sensíveis na saúde mental - Contribuições de Reggio Emília para uma pesquisa a/r/tográfica. Aurora: revista de arte, mídia e política, São Paulo, v.12, n.35, p. 87100, jun.-set.2019. 


\section{Dialogia}

SURUAGY, Cláudia Calheiros da Silva; FRANCISCO, Deise Juliana. A produção de vídeo por pessoas em sofrimento psíquico

SIMONDON, G. El modo de existencia de los objetos técnicos. Buenos Aires: Prometeu Libros, 2007.

TRINDADE, C.; BECKER, A. Aprendizagem colaborativa mediada pelo blog do moodle. Anais do VIII Encontro Virtual de Documentação em Software, v. 1, n. 1, junho, 2011. Disponível em: <http://www.textolivre.org/viiievidosol/forum/90.pdf.> Acesso em: 15 nov. 2017.

Recebido em: 29 mar. 2020/ Aprovado em: 06 jul. 2020

\section{Cite como}

(ABNT NBR 6023:2018)

SURUAGY, Cláudia Calheiros da Silva; FRANCISCO, Deise Juliana. A produção de vídeo por pessoas em sofrimento psíquico. Dialogia, São Paulo, n. 35, p. 263-279, maio/ago. 2020.

Disponível em: https://doi.org/10.5585/dialogia.n35.16909.

\section{American Psychological Association (APA)}

Suruagy, C. C. S., \& Francisco, D. J. (2020, maio/ago.). A produção de vídeo por pessoas em sofrimento psíquico. Dialogia, São Paulo, 35, p. 263-279.

https://doi.org/10.5585/dialogia.n35.16909. 